\title{
Liderazgo y creencias educativas
}

\author{
Jaime Martínez Toro29 \\ jaimemart89@gmail.com
}

Artículo recibido en marzo y aprobado en mayo de 2017

\section{Resumen}

Con este texto se pretende poner en cuestión una serie de creencias arraigadas en los educadores adultos y proponer una visión abierta y respetuosa cuya base sea la libertad y el amor. Entiendo por educadores/as todas aquellas personas implicadas de forma directa o indirecta en la educación de un menor, dentro y fuera del aula, partiendo de que toda interacción puede vivirse como una oportunidad educativa. Partiré del relato personal de empoderamiento de un joven desde sus cualidades frente a las expectativas y cualidades que él consideraba parte de un líder, para pasar después a comentar las "creencias educativas" adultas relacionadas.

Palabras clave: creencias, libertad, empoderamiento, educadores, joven, líder, educación no formal.

\section{Abstract}

In this article are discussed several beliefs rooted in the adult educators and is proposed an open and respectful vision whose base would be love and freedom. I understand as educators people who are involved in a direct or an indirect way with the education of an underage person, inside and outside the classroom, comprehending all the interactions could be lived as an educational oportunity. I will start with a personal story about the empowerment of a youngster from his qualities opposing his own expectations and qualities about being a leader to comment those adult "educational beliefs" after.

29 Licenciado en Historia por la universidad Complutense de Madrid y titulado como monitor de Ocio y Tiemplo Libre. Mi formación universitaria me ha aportado una visión crítica de la realidad y el convencimiento de que no existen saberes absolutos; por otro lado, mi título como monitor me ha dado la oportunidad de entrar en la educación no formal y experimentar relaciones más horizontales con jóvenes, niños y adultos de la tercera edad. Todas esas líneas rectas y currículos inamovibles dejan muy poco espacio para la creatividad y el amor pedagógico. 


\section{La inseguridad como herramienta de cambio}

Hablar de la inseguridad como herramienta es algo extraño, y tengo que admitir que no es tanto la inseguridad como la capacidad de evidenciarla lo que me ha ayudado en el acercamiento a jóvenes, en este caso, y a niños o ancianos en otros. La inseguridad es el terreno vedado de los adultos hechos a sí mismos, profesionales, que saben todo lo necesario para desenvolverse en la vida. Y justo en ese tabú radica la eficacia de reconocerse incapaz o inseguro como adulto frente al resto de colectivos, es decir, todos los no adultos, que viven la inseguridad como una constante. Voy a relatar mi experiencia de empoderamiento de un joven desde el grupo juvenil CEFA (Campamentos Ecuatorianos Fe y Alegría) para poder entender mejor esto de la inseguridad evidenciada y desarrollar otros temas de interés dentro de la educación formal y no formal.

Voy a situar brevemente el contexto de esta experiencia de acompañamiento. Yo era el asesor del grupo juvenil CEFA de un centro educativo. Es decir, el adulto responsable-referente de ese grupo. Este grupo está formado por estudiantes voluntarios de $8^{\circ}$ de básica hasta $3^{\circ}$ de bachillerato. En el caso concreto de ese centro educativo, el grupo se reúne una vez a la semana en dos secciones diferentes por la incompatibilidad de horarios. El lunes la sección de bachillerato y el martes la de la básica superior. En todo momento me referiré al joven de esta historia como "R." y al resto como grupo sin especificar sus nombres.

R. es un chico de $3^{\circ}$ de Bachillerato (17 años). Dulce, tímido, extraordinariamente creativo, con una gran sensibilidad artística, que se mueve con soltura en grupos pequeños y, paradójicamente, sabe encandilar desde la timidez. ¡Qué mala suerte, justo ese año ha sido elegido como jefe de campamento por el resto de "cefistas"! (miembros del grupo CEFA) de su zona! Esto significa hablar a grupos grandes, dirigirlos, ser un referente ético, disciplinario, y además resultar divertido, atractivo, capaz de reprender y entretener. Esto escapa de la concepción y el deseo de la mayoría de adolescentes, en una etapa en la que "adolecen", es decir, sienten que les falta esto y aquello para sentirse seguros. R. no era una excepción. 
Yo, por mi parte, era un recién llegado, desempeñaba el rol de asesor, un adulto de referencia para el grupo CEFA, de uno de los centros educativos. En mi ignorancia, confié en que el chico sabría desenvolverse ya que era un veterano en el grupo, y llegamos a un primer campamento, él con todos sus miedos e inseguridades. Ahí realmente comprendí pronto que R. no se hallaba en su nuevo rol. "Es que no sé qué decirles." "¿Cómo les digo?" "Es que no me hacen caso", etc. La coordinadora del campamento y yo le dábamos consejos sobre la marcha. Pero el ritmo del campamento no permitía los tiempos y el cuidado que necesitaba este chico. Me fui del campamento con esto muy claro, así que empecé a pensar en cómo atacar este problema.

El siguiente lunes invité a R. a hablar de la experiencia al resto del grupo; qué le gustó, qué se le hacía complicado, qué dudas tenía, etc. Yo compartí mis propias complicaciones, miedos, dudas, anécdotas como monitor de campamentos en España, y algunos elementos importantes para dirigirse a un grupo que necesitábamos cuidar como la explicación de una comanda y la energía que queremos transmitir para cada una de esas comandas (no es lo mismo hacer una actividad reflexiva, que una dinámica para activarse, o una actividad que invite a la relajación). También reflexionamos acerca de la imagen que tenían de líder para salir del enunciado buenista de "¿cómo debe ser un líder?" donde todos hablamos de valores abstractos que muchas veces no nos conmueven ni nos exigen algo nuevo. Al plantearles que me describieran cómo se imaginan a un líder, los adjetivos que fueron surgiendo eran, por ejemplo, "un hombre grande", "fuerte", "que sepa mandar", "alguien imponente", "que hable duro", "mayor".

Para matizar esto último les pregunté si mayor que yo (tenía 27 años en ese momento), y varios aseguraron que sí. Concluimos que la imagen mental de líder es un señor de unos cuarenta años que manda mucho y da un poquito de miedo. Yo les planteé que no es la idea de líder que se buscaba en el CEFA y que sería interesante que pensaran en por qué su imagen no se corresponde con la de una mujer, alguien más joven, o alguien que no sea "imponente". Por último, y esto les gustó mucho, les revelé que el poder 
(como capacidad de influencia en otros) es algo mucho menos estático de lo que parece, y que de hecho ellos, por el simple hecho de ser más jóvenes, tenían más poder en ciertas situaciones que los propios adultos. Les hablé de que la cercanía en edad significa una mayor identificación, que los chicos de la básica ven en ellos un referente a imitar mucho más atractivo que sus padres, o cualquier otro adulto, lo que les otorgaba mayor poder sobre ellos, y por tanto, podían gestionar mejor esos grupos que los adultos.

Esta sesión no fue en balde porque me permitió acercarme al grupo al hablar de una manera horizontal, reconociéndome con dudas y miedos como ellos y reconociéndolos a ellos en esas dudas y miedos, y lo central de esta sesión fue invitar a R. a una sesión en solitario conmigo para practicar técnicas de voz, dinámicas y solucionar dudas sobre cómo llevar grupos. Esto me daba la oportunidad de trabajar cuestiones externas (la voz, la energía en las dinámicas, la técnica, puramente corporal) para poder tratar cuestiones internas (emociones, inseguridad, la asunción del personaje-líder, etc.).

Llegó la mencionada sesión y fue tremendamente fructífera. Los ejercicios desde el cuerpo (tomar el espacio, proyectar la voz, etc.) daban herramientas válidas a R. Llevaba tiempo observándole como al resto del grupo, y vi que disfrutaba del baile, así que el cuerpo fue un acierto para trabajar con él. Practicamos algunas dinámicas con niños de $3^{\circ}$ y $4^{\circ}$ de básica (7-9 años), y vi que le gustaban los niños pequeños aunque se sentía algo raro al "crear" la situación, al ser algo artificial por buscar nosotros a los niños y proponerles algo que no podían rechazar, al proponerlo un estudiante mayor,:

“¿Quieren jugar?" Esto le permitió darle más confianza, ver que él era capaz de dirigir un juego y un grupo concreto. Pero lo más interesante de aquella mañana fueron las conversaciones, las pequeñas frases y dudas llenas de valiosísima información que se daban entre ejercicio y ejercicio. Por ejemplo: "Es que yo no sé hacer como usted o la coordinadora", "Sí con los niños chiquitos muy bien, pero luego con los otros..."

Esto me llevó a entender algunos de sus grandes miedos, o por lo menos de los que R. me creía con capacidad de solucionar. 
- La primera frase me llevó a lanzar una mirada apreciativa sobre él y a romper la idea de líder como algo monolítico. Le dije que tanto la coordinadora como yo habíamos creado un personaje de líder mediante la práctica, pero sobre todo, desde lo que somos. Yo pregunto mucho al grupo porque creo en el saber colectivo, en limitar mis opiniones para no condicionar al grupo, porque creo en la horizontalidad, por ejemplo. Así que le dije lo que yo veía de positivo en él, incluso aquellas cosas que él sentía contrarias a la idea de líder. "Eres dulce en tu manera de hablar, no tiene sentido que cambies eso porque no te vas a sentir cómodo dando gritos como un militar". "Eres tranquilo, pero eso se transmite y es positivo, ayuda a que el grupo esté también tranquilo". Todo ello destacando qué cosas sí tenía que trabajar: el volumen de la voz, la claridad del mensaje y la atención del grupo.

-La segunda frase me llevó a cuestiones concretas sobre cómo manejar la atención en el grupo de manera no autoritaria. Le hablé entonces de situarse cerca de las zonas donde hubiera gente hablando, para que al verle y sobre todo al ser vistos por el resto de compañeros, sintiesen que deben callarse. En este mismo sentido le aconsejé hacer mención de las personas que no están atentas en tono de humor sin caer en el menosprecio para de nuevo llamar la atención del grupo hacia quien está fuera de la dinámica grupal. Por último, le aconsejé sorprender desde lo positivo, acercarse a alguien que está hablando cuando no debe y frotarle la espalda con suavidad, hablarle tranquilo "Ya compa, estamos con esta actividad", la sorpresa al ser tratado amablemente por algo que normalmente se castiga y la presencia de una autoridad reconocida por el grupo hace que la persona sienta que debe ubicarse.

Todo ello, y en especial el clima de confianza en que se dio, generó cambios dentro de R. Sentía la curiosidad, las ganas y la energía para probar al menos alguno de esos trucos y novedades que habíamos aprendido y puesto en práctica, pero por encima de todo estaba resuelto a pasar todos esos elemento por su propio prisma, estaba decidido a ser líder a su manera.

Poco antes de subirnos al autobús para el siguiente campamento en que sería jefe, lo reuní junto a otro chico y otra chica que lo acom- 
pañarían como miembros del equipo de materiales (auxiliares de los jefes y también figuras de referencia para los acampados). Les recordé que eran un ejemplo, que todos les iban a mirar y a seguir para bien o mal y sobre todo que confiaba en ellos para que estuvieran a la altura. El campamento marchó francamente bien. Entre otras cosas porque fue un campamento con pocos participantes y eso nos ayudó a todos en todo lo que se refiere a llevar grupos. Los chicos de materiales destacaron cada uno a su manera y R. no decepcionó. Siempre habrá cosas que mejorar, pero lo hizo muy bien. Principalmente porque disfrutó de su rol, y lo hizo porque se encontró a través de su rol, no era R. imitando posturas, voces, chascarrillos o frases que él consideraba propias de líderes por haberlo visto en sus referentes, era R. con sus propias posturas, voces y chascarrillos.

En lo que siguió de año su propio personaje-líder se dejó ver en más ocasiones, dentro y fuera de los campamentos. Es muy gratificante ver una incidencia tan clara, pero precisamente por ser algo evidente estoy convencido de que sólo puse el broche a un proceso muy largo de educación y empoderamiento desde su casa, pasando por su propia experiencia de vida y por su historia en el CEFA.

\section{¿Qué creencias proyectamos a los jóvenes en Ecuador?}

Primero concretaré el término "creencia". Aquí hablo de creencia como la entiende Ortega y Gasset. El filósofo explica la creencia como una idea interiorizada a tal punto que marca nuestras actuaciones y relaciones con el medio de forma consciente o inconsciente. Por ejemplo: Todos los adultos creemos en que al pisar el suelo no nos vamos a hundir, por eso andamos con tranquilidad y sin miedo (Ortega y Gasset, 1934). Es un ejemplo muy obvio, pero en nuestro proceder nos mueven creencias menos comprobadas, como por ejemplo las relacionadas con la dieta: "Si no lo tomas rápido se le van las vitaminas". En la mayoría de los casos no comprendemos ni conocemos el proceso físico-químico de estas aseveraciones, pero por si acaso y ante la repetición de nuestras personas cercanas de esta creencia, apuramos el vaso de jugo de 
naranja en lugar de tomarlo pausadamente; por lo tanto, la creencia condiciona nuestra forma de relacionarnos con ese vaso de naranja.

\section{¿Cuáles son nuestras creencias en materia educativa, formativa, respecto a los jóvenes?}

No puedo recoger todas las creencias sobre la educación con jóvenes en Ecuador, pero sí explicitar algunas recurrentes y que a mi juicio dificultan el proceso hacia jóvenes autónomos y libres. Estas creencias las he encontrado dentro de los mismos jóvenes, algunos docentes, y padres y madres de familia. Esto solo es una guía que invita a cuestionar nuestras creencias y a buscar una forma de actuar adecuada, personalizando a cada educando, y no pretendo realizar una guía etnocéntrica sobre lo que tiene y no tiene que ser la educación.

- "Respeto a la autoridad" (sin matices). Es muy necesario reflexionar sobre el poder y hacer pensar sobre el poder a los jóvenes. Entender que la autoridad es buena por el hecho de ser autoridad es muy peligroso ya que es negar la desigualdad de poder (en cuanto posibilidades, derechos, etc.) entre diferentes etnias, países, géneros, etc. (Platero, 2013). Por otro lado, desprotege al menor frente a posibles abusos y aumenta las probabilidades de convertirlo en un abusador (Mesa-Gresa y Moya-Albiol, 2011). Desde la óptica de liderazgo damos alas a cualquier tirano a hacer lo que quiera "porque es la autoridad" y a generar un sentimiento revanchista en el que el sometido somete dentro de sus cuotas de poder y lo justifica desde el respeto a la autoridad.

Algunos adultos utilizan esta frase buscando la comodidad que otorga el control del grupo, y por ese pequeño espacio están siendo portavoces del mensaje destructor de la sociedad de consumo, no eres parte de las personas con poder porque no tienes (un cargo, dinero, bienes materiales), no eres parte de la riqueza, no mandas, tú y tu existencia como pobre es una "desgracia". Generando frustración y obsesión por triunfar de cara a la sociedad; conseguir dinero, estatus social. Lo que, en la mayoría de contextos, más aún en contextos de bajos recursos, es muy difícil que ocurra a la velocidad y en los términos de una fantasía 
adolescente. Con lo que exponemos aún más a chicos y chicas vulnerados a buscar una salida a esa frustración en las drogas o el alcohol o a desarraigarlos de su medio desde la vergüenza social y el arribismo de clase (Carrasquilla, 2000).

Desde mi punto de vista, entiendo el respeto como algo previo y a todas las personas, no a las que representan la autoridad. Personificar en lugar de etiquetar es un ejercicio muy necesario para poder romper con las conductas discriminatorias e injustas dentro del grupo. Si yo personifico a mi padre, me cuesta menos pensar y expresar que lo que dice tiene sentido o no lo tiene, estoy horizontalizando la relación con él, sin dejar de entender que es mi padre. Hacer las relaciones más justas, más próximas, es aplicar la visión de derechos a las relaciones. No se trata de "perder el control del grupo" y dejar que te pierdan el respeto o de "dar demasiada confianza", sino de que todos nos tratemos como personas merecedoras de respeto por el hecho de serlo, lo que sería el primer paso necesario. Luego, hablaríamos del respeto al grupo, al momento o a la situación. Por dar un ejemplo fuera del silencio en el aula: una falta de respeto a una situación de juego sería boicotearlo poniendo malas caras y llamando la atención para que todo el mundo vea lo poco que te apetece jugar y la atención cambie de eje. Hay que inculcar y ejercitar el respeto y cuidado por uno mismo, así como la empatía, para generar la necesidad de respeto hacia el otro o el reconocimiento del otro como persona.

Como dice Raquel Platero (2013) "Cuando no somos capaces de reflexionar sobre nosotros mismos, tendemos a despersonalizar a los demás" (p.295).

\section{- "Hace falta un líder/autoridad que organice/ponga orden" Esta afir-} mación deja fuera, en la mayoría de los casos, a los jóvenes. En la imaginación colectiva tiende a confundirse autoridad con adulto. Esta idea genera dependencia en los jóvenes que se creen incapaces de asumir el liderazgo de un proceso si no hay un adulto que prácticamente dirija y encorsete el mismo. Hace falta poner el foco en la autogestión y mostrar referentes de juventud organizada por su cuenta para realizar acciones concretas o proyectos continuados. 
La autogestión, también tiende a limitarse como concepto. Es mucho más que recoger fondos, es todo aquello que realizamos por nosotros mismos como grupo para nuestro grupo. El reto a superar al entregar un proceso o una acción a los jóvenes es el siguiente: no va a salir como un proceso dirigido por adultos, va a ser diferente. Esto se vive como una dificultad para el adulto si de veras no quiere intervenir, y como una frustración para el joven que tiene expectativas de algo al estilo de un adulto. Por ello hay que insistir en referentes juveniles interesantes: películas de sensibilización hechas por jóvenes, arte urbano, marchas, manifestaciones, etc. Con la certeza de que otras personas jóvenes han logrado acciones es más sencillo que nuestro grupo se lance a hacerlo. Existen numerosos ejemplos, como la acción Arriba los de debajo de los raperos Todo Copas $^{30}$.

El arte juega un papel central como lenguaje. Es un lenguaje sin las restricciones propias del lenguaje oral, que además los niños no han tenido tiempo de dominar y muchos jóvenes y adultos no han tenido la oportunidad de desarrollar mejor.

Encontramos además que la información recibida desde el arte es más rica y honesta

(estado emocional, forma de pensar, cultura, tiempo del "usuario"). (Echeverría, 2013).

Desde el punto de vista educativo el arte permite descubrir nuestras propias capacidades, fomenta la creación colectiva, la generación de discursos propios, y hasta la búsqueda de fines para el mismo desde el colectivo que lo utiliza (Tobón, Gaviria y Ramírez, 2011).

El hecho de "soltarles la mano" a la hora de generar una acción es algo imprescindible para que hagan de esa acción algo político y genuino. Los jóvenes necesitan reconocerse como sujetos históricos y sujetos

30 Videoclip, canción y acción en el barrio de "La Perserverancia" de Bogotá (Colombia) frente a la gentrificación creciente. Recuperado de http://www.caldodecultivo.com/Arriba-los-de-Abajo 
políticos para vencer la idea de que el joven en política no es más que un instrumento para dar una cara "más fresca" del partido o la institución de turno (Cerbino y Rodríguez, 2005). Si esperamos líderes que generen cambios, tenemos que dejarles liderar y realizar acciones, preferiblemente con un contenido político.

- Yo hago esto porque me ha funcionado siempre. El mundo es cambiante y la cultura también. Si bien es cierto que existen factores fundamentales o clásicos que nos ayudan como una base para tratar este $\mathrm{u}$ otro colectivo en función de su edad $\mathrm{u}$ otras características, nunca debemos perder de vista que la cultura, como la experiencia juvenil es algo en continuo movimiento y que cada individuo es una persona diferente con una historia, unos gustos, una experiencia vital concreta y sobre todo con necesidades diferentes. La clave para trabajar con personas es identificar la necesidad de esas personas y sobre todo la manera de satisfacerla respetando su historia, gustos, etc. (Wilde, 2002a).

Especialmente no debemos confundir nuestras necesidades con las necesidades del educando, yo quizás necesito jóvenes tranquilos, pero algunos de ellos pueden no necesitar tranquilidad, si no movimiento, ser escuchados, etc. Aquí entra en juego una negociación seria y unos pactos que expresen las necesidades del grupo, ya no de cada individuo, éstos podrían satisfacerse en otros espacios de acompañamiento.

Por último, el deseo de innovar es un imperativo de lo que llamamos amor pedagógico. Me quiero, amo mi trabajo, amo a mis alumnos. Por el amor a mi persona y a mi trabajo cuando puedo me formo, leo, y descubro qué han logrado mis compañeros aquí y allá y qué me pueden aportar, y por el amor a mis alumnos investigo y cuestiono mis estrategias y mis contenidos para con ellos.

- Soy como uno/a más, son mis niños, etc. Expresiones como estas se escuchan mucho y con mucho cariño por parte de docentes muy valiosos. La cuestión aquí es que el lenguaje crea realidad y sobre todo que puede haber una confusión de roles importante.

El lenguaje crea realidad en tanto que enunciamos a través de él nuestra relación con el mundo. Es por ello que hay un esfuerzo creciente 
por el lenguaje inclusivo, porque por ejemplo, utilizar la expresión "inválido" o "minusválido" habla de personas que no tienen valor por tener una discapacidad; y generar en ellas la creencia de que literalmente

"no son válidas" o valiosas tiene consecuencias psicológicas evidentes en la vida de esas personas.

Así mismo tiene consecuencia en nuestras relaciones con los educandos expresar frases como "Mis niños", "son como mis hijos", "soy como el papá/como la mamá", "soy uno más", "a mí me lo cuentan todo", "somos panas".

Nuestros educandos necesitan un referente distinto a sus referentes habituales, ni somos otro joven o niño, ni somos sus padres. Tengan o no estos referentes no necesitan que un educador asuma los roles mencionados. Es injusto y confuso. No vamos a vivir con ellos, no podemos solucionar o ayudar en muchos de sus problemas familiares o personales, no vamos a compartir su lenguaje ni su forma de mirar el mundo, no vamos a marcar castigos, premios y pautas correspondientes a sus padres o a sus tutores, y definitivamente, no vamos a ser sus "panas". Podemos conseguir confianza, respeto, límites, cariño, etc. sin situarnos en roles que no son los nuestros, somos lo que somos, educadores, con eso es suficiente. Además por nuestra salud mental y la de ellos es importante que exista una distancia y que los roles estén muy claros. A la larga, es interesante ver que este rol distinto nos da una posición muy interesante para acompañar sin juicios problemas de la vida adolescente como los derivados de la sexualidad, las relaciones, el existencialismo, etc.

- Debo transmitir mis ideas sobre el mundo. A todos los adultos nos sobrecoge el panorama de desinterés por los asuntos que consideramos claves para el desarrollo de una sociedad mejor y caemos en afirmaciones tremendistas: "No saben nada", "no se dan cuenta", "a dónde vamos a parar", etc. Sin entrar en lo evidente de que cada adulto tiene unas ideas y concepciones muy distintas sobre ese mundo mejor, debemos hacer un ejercicio de empatía, situarnos en nuestro yo de 15 o 14 años y ser honestos con lo que nos interesaba y sabíamos. Quizá desde ahí apreciaremos que teníamos intereses complejos por el 
mundo. De todas maneras, aunque nuestro grupo de jóvenes aparentemente sólo esté pensando en sexo y rumba, cualquier enunciado inicial es interesante para hilar otros temas. Hablar de relaciones tóxicas y sanas, debatir sobre ellas, tomando por base el interés en las relaciones románticas ya es un trabajo que da para mucho, y como ese, existen millones de temas más ya que contamos con cerebros adolescentes, que están preparados para el pensamiento simbólico (Wilde,2002a).

Nuestro rol central es fomentar el debate, proporcionar el espacio, la confianza, para que ellos aprendan a "filosofar", a manejar lo simbólico desde su propio lenguaje y a crear sus propias ideas. "La filosofía contribuye a hacer de los actores sociales, sujetos de su propio destino."(Echeverría, 2013, p. 109). Si sentimos la necesidad de aportar una idea siempre debemos hacerla como un miembro más del debate, desde el "yo"(yo creo, yo opino), sin abusar de nuestra autoridad creando ideas válidas frente a sus ideas no válidas.

El fin último de este "filosofar" es acostumbrar a los educandos y a nosotros mismos a la incertidumbre y a la búsqueda de respuestas-soluciones propias (De la Garza, 2013) ,que nos llevarán a otras preguntas o incertidumbres y de nuevo a la búsqueda de soluciones propias haciendo de la vida una vivencia investigativa (Agúndez, 2013).

Por otro lado, hay que comprender el medio y el momento histórico de nuestros educandos. Voy a dar algunos datos que he podido observar.

- A nivel macro: Se encuentran expuestos a una cantidad de información difícil de procesar en el ritmo al que les llega, un capitalismo más agresivo como consecuencia de las respuestas políticas en diferentes países del mundo como Canadá, España, Egipto, Túnez, etc. ${ }^{31}$, un desprecio hacia la lucha social como elemento distorsionador del "buenvivir" proporcionado por el Estado, una proyección de futuro castrada

31 Me refiero aquí a movimientos populares que reaccionaron contra sus gobiernos entre 2010 y 2013 como el 15-M en España, la Primavera Arce en Canadá o la Primavera Árabe en Egipto, Túnez y otros países musulmanes. 
por las cifras de desempleo donde la Universidad o la Escuela no asegura un proyecto de vida frente a la corrupción o el clientelismo, hay una desconexión total entre el consumidor y todo el proceso de producción por lo que es muy difícil empatizar con las condiciones laborales o con el impacto socioecológico de consumir este o aquel producto sin investigar sobre ello (Agúndez, 2013). Los medios de comunicación promueven, crean y recrean una imagen de adolescencia consumista e irreflexiva que canaliza su rebeldía a través del individualismo que no tiene repercusión política o social (sexo prohibido, sustancias prohibidas, carreras prohibidas, etc.) y recientemente hay un esfuerzo notable por alargar esta adolescencia en la vida adulta creando consumos e intereses parecidos. Respecto a los derechos humanos, la publicidad y algunas instituciones promueven discursos vacíos y simplistas en los que "queda mucho por hacer", "antes se estaba peor" pero no se concreta, estudia y reflexiona acerca de cómo se han logrado esos cambios que han posibilitado vivir mejor ni se especifica claramente cuáles son los retos en esta materia de manera concreta.

- En lo micro: cabe estudiar cada contexto. En el caso de Guayaquil, concretamente el contexto de Monte Sinaí, encontramos una brecha generacional importante entre los padres y madres y sus hijos e hijas. Sus universos conceptuales son incompatibles. Hay una visión negativa del joven que se mira desde su potencialidad como drogadicto, problemático, lujurioso, ladrón, vago, etc. y se proyecta sobre él/ella un control asfixiante y todos esos miedos una y otra vez, haciendo estas medidas en muchos casos contraproducentes. No existen espacios de recreación para jóvenes, ni espacios estimulantes gratuitos (centros culturales, ludotecas, etc.). Existe una sensación de inseguridad fomentada por la tele y el control parental que hace que los jóvenes, aun pudiendo hacerlo, no ocupen la calle y la hagan más segura. El racismo y el sexismo están a la orden del día, con lo que la discriminación por ser joven se dobla o triplica al ser mujer, negro, extranjero, etc. Existe miedo a la calle, al barrio, y por ende a la gente que forma parte de él, por lo que la unión entre vecinos y "ocupar" las calles en un sentido positivo es difícil. La violencia intrafamiliar y en las relaciones cotidianas es habitual y está normalizada. La política sigue un discurso partidista y hay una larga tradición de dependencia creada por los poderes estatales de lo que deriva una indefensión aprendida casi crónica en 
la que crecen y se identifican estos jóvenes a pesar de existir comités barriales.

- Pobrecitos. Este apartado está especialmente dirigido para aquellas personas que trabajan con colectivos en riesgo de exclusión, de escasos recursos, etc. Existen dos confusiones a señalar a mi juicio que al proyectarse desnudan al educando de su dignidad:

1- No son pobrecitos, son personas con sus circunstancias y como personas son capaces de vivir y luchar su existencia como todas. Por supuesto que es legítimo ayudar a quien se encuentra en una situación de miseria o abandono total. Pero a partir de ahí el trabajo debe ser horizontal, sin "regalar" de forma paternalista tiempo, dinero, juguetes, etc. Cuando regalamos nos colocamos automáticamente en una posición de superioridad en la que empobrezco a la persona arrancándole su dignidad. Si deseamos ayudar a una persona en esos términos tengamos la decencia de establecer una relación con ella. Demos nuestro tiempo, nuestro cariño, y entonces sí, desde la amistad, regalemos lo que queramos. Porque estaremos actuando en términos muy diferentes en los que no pisoteamos la dignidad de las personas, ni les anulamos su capacidad. Además, es mucho más justo ayudar a un amigo, que ayudar de manera impersonal, es posible que uno pueda ayudar a todos sus amigos y aportar un grano de arena más profundo en la práctica de valores que aportar a muchos pobrecitos sin poder ayudar a la totalidad de estos y además sin aportar ningún cambio a la problemática de la pobreza. Caritas, el término latino del que proviene la palabra "caridad" significa "estima, afecto, amor" 32 ¿qué afecto puede haber en una relación de poder tan obvia en la que yo te doy a ti porque eres un pobrecito? ¿La de un perro y un amo? Yo, personalmente no creo en esa relación de "afecto" entre personas.

2- Los límites no son violencia, la falta de estos sí. Por maltrato a un menor se entienden "tanto la falta de atención adecuada (negli- 
gencia o abandono), como los hechos que lesionan la salud física del menor (maltrato físico o abuso sexual), así como las acciones que atentan contra su salud mental (maltrato psicológico)" (Mesa-Gresa y Moya-Albiol, 2011, p.489), a pesar de la claridad de estos términos hay muchas personas que confunden los límites con la violencia cayendo en la primera forma de maltrato, la negligencia. Todas las personas para lograr un correcto desarrollo cerebral, físico, intelectual, psicológico y social necesitamos de cariño, de la satisfacción de nuestras necesidades y de límites con amor que delimitan los marcos de libertad y seguridad necesarios para desarrollarnos y vivir en sociedad. Las leyes naturales nos limitan, por ejemplo, no podemos estar en dos lugares a la vez o volar sin la ayuda de máquinas, la vida se vive dentro de límites. Los límites que son necesarios en el desarrollo de la persona marcan el espacio seguro para crecer y que permite crecer al resto sin violar su espacio, encuadrado en una dinámica de amor y respeto (Wilde, 2006b). Marcar limites supone decir "basta" a un comportamiento que invade el espacio de libertad de otros, incluyendo el de los adultos. El problema que he observado en Guayaquil es que hay una confusión entre establecer límites y la agresión verbal, ya que hay dinámicas de violencia y falta de límites en muchos hogares y que se considera como una consecución lógica que tras un alzado de voz, un grito (cuando el adulto está irritado) va a llegar una agresión física. Además de entender una dinámica de derechos sin contemplar al adulto como una persona con necesidades y derechos. Colocándolo en una situación irreal en la que los padres demandan autoridad del educador y a la vez una suerte de "respeto condicionado a posibles denuncias" que se traduce en una extraña deferencia hacia el joven-tirano, que debe ser mimado en sus derechos, en lugar de trabajar juntos por un esquema coordinado de límites dentro del marco de derechos de niños y jóvenes.

\section{- No se puede trabajar con estos niños porque tienen un contexto...} A veces resulta frustrante trabajar con niños y jóvenes que vienen de hogares desestructurados; por suerte estamos rodeados de experiencias y trabajo con todo tipo de colectivos que dicen lo contrario. Hay que tomar conciencia del daño a nivel neurológico derivado de la vio- 
lencia dentro de los hogares para entender que el desarrollo del cerebro de niños y jóvenes vulnerados o violentados es diferente y puede llevar a manifestar problemas que tienen relación directa con dificultades en el aprendizaje, con el lenguaje, la ética y la convivencia. Algunos expertos manifiestan que el $70 \%$ del desarrollo cerebral depende de las interacciones que tengamos con otras personas (Cortina, 2013), por otro lado hay estudios que prueban que "la experiencia y lo experimentado [...] determinan qué genes llegan a expresarse, cómo lo hacen y cuándo" (Bilbao, 2011, p.4). Por otro lado, el consumo de drogas - la hiperresponsabilización de algunas zonas del cerebro encargadas de dar respuesta a estímulos estresantes pueden generar dinámicas cerebrales que afectan al comportamiento como la "irritabilidad límbica"( Mesa-Gresa y Moya-Albiol, 2011).

No manifiesto esto como un elemento negativo, lo hago para comprender de dónde podemos estar partiendo y que no podemos manejar ni solucionar todo. Poner coherencia y valores en la vida de nuestros educandos así como proporcionarles espacios de reflexión, crítica, expresión y en definitiva de libertad es nuestro aporte para los jóvenes, otras funciones corresponden a terapeutas, padres y madres, políticos, etc.

\section{Conclusiones}

Quiero terminar con una referencia literaria que para mí ejemplifica el proceso de concienciación y libertad de un individuo, por ejemplo un joven. Hablo del cuento "Amoría" de la editorial Anselmo Lorenzo (Litvak, 2003). Este cuento relata el naufragio de un barco español en época de la conquista en una isla desierta y todo el proceso que parte desde que establecen una microsociedad espejo de lo que conocían, con sus injusticias y jerarquías, hasta crear una sociedad horizontal e idílica. No espero resultados idílicos porque somos personas, y fallamos y nos enriquecemos con los fallos y la frustración que nos lleva a crear nuevas soluciones, pero si espero que cada comunidad, cada grupo, encuentre sus soluciones, se haga dueño de su destino y elija, en libertad, su propio camino. 


\section{Referencia}

- Agúndez, A. (2013) ¿Es la educación del consumo una educación política necesaria? Pp. 29-51 en Otra educación es posible. Rezola, R. (ed) Barcelona: Laertes

- Carrasquilla, F. (2000). Escuchemos a los pobres. 2a ed. Quito: Tierra Nueva.

- Cerbino, M., Rodríguez, A. (2005) Movimientos y Máquinas de guerra juveniles. Nómadas, 23, 112-121.

- Cortina, A. (2013) ¿Solo la libertad es el camino hacia la libertad? Pp. 75-97 en Otra educación es posible. Rezola, R. (ed) Barcelona: Laertes

- (2013) ¿Cómo son los mundos de Filosofía para Niños? Pp. 99-120 en Otra educación es posible. Rezola, R. (ed) Barcelona: Laertes.

- Litvak, L. (2003). El cuento anarquista (1880-1911): antología. Madrid: Fundación de Estudios Libertarios Anselmo Lorenzo.

- Mesa-Gresa, P. y Moya-Albiol, L. (2011). Neurología del maltrato infantil: el "ciclo de la violencia". Rev. Neurol, 52(8), 489-503. [En línea] Recuperado de: http://www.neurologia.com/articulo/2009256

- Ortega y Gasset, José. (1934). Ideas y Creencias. Biblioteca Virtual Omegalfa 2010. Recuperado de: www.omegalfa.es

- Platero, R. (2013) ¿Cómo nos transforma el feminismo? Pp. 279-298 en Otra educación es posible. Rezola, R. (ed) Barcelona: Laertes.

- Rezola, R.(et al.). (2013). Barcelona: Laertes.

- Tobón, F.Á., Gaviria, N., Ramírez, J.F. (2011). La lúdica como método psicopedagógico: una experiencia para prevenir la farmacodependencia en jóvenes. Avances en Psicología Latinoamericana; 30(1): 81-92.[En línea] www.scielo.org.co 
- Wilde, R.y Wilde, M. (2002a). Educar para ser: una respuesta frente a la crisis. 4a ed. rev. Quito: Fundación Educativa Pestalozzi.

- Wilde, R. (2006b). Libertad y límites. Amor y Respeto. Barcelona: Herder.

\section{Webs, periódicos y audiovisuales}

-Grupo Caldo de Cultivo. Recuperado de: www.caldodecultivo.com/ Arriba-los-de-Abajo [Consultado el 10/03/2017 15:00. Arriba los de Abajo.]

- Cáritas Arquidiocesana de Guatemala. Etimología de Caridad. Recuperado de https://caritasarquidiocesana.org/etimilogia-de-caridad [Consultado el 12/03/2017, 15:00 h. ] 